\title{
El reto de la comunicación: liderazgo comunicacional y herramientas negociadoras
}

\author{
Olga Cavallucci \\ Universidad San Francisco de Quito \\ olgacavalluccid@gmail.com
}

Fecha de presentación: 5 de marzo de 2015 • Fecha de aceptación: 17 de diciembre de 2015

Artículo de opinión 


\section{Resumen}

Este artículo se desarrolla alrededor de dos ejes centrales: la comunicación y el arte de la negociación como elementos resolutivos del liderazgo comunicacional, lo que, a su vez, da lugar a un novedoso concepto: el liderazgo feliz.

El punto de partida es que todo ser humano tiene un factor innato y un set de elementos adquiribles, es decir, que pueden trabajarse a través de la práctica y de la implementación de algunas herramientas: concientización, comportamiento, imagen, escucha activa y empatía.

Palabras clave: negociación, liderazgo, comunicación, liderazgo feliz.

JEL: I31 Bienestar general, necesidades básicas, nivel de vida, calidad de vida, felicidad.

\section{Abstract}

This article revolves around two central axes: communication and the art of negotiation as operative elements of communication leadership, which in turn gives rise to a new concept: the "Happy leadership".

The starting point is that every human being has an innate factor and a set of purchasable items, ie, that can be worked through practice and implementation of some tools: Awareness, Behavior, Image, Active listening and empathy.

Keywords: Negotiation, leadership, communication, happy leadership.

JEL: I31 General well-being, basic needs, standard of living, quality of life, happiness.

\section{Resumo}

Este artigo gira em torno de dois eixos centrais: comunicação e a arte da negociação como elementos geradores de liderança comunicação, que por sua vez dá origem a um novo conceito: a "liderança feliz".

O ponto de partida é que cada ser humano tem um fator inato e um conjunto de itens compráveis, ou seja, que pode ser trabalhado através da prática e implementação de algumas ferramentas: a consciência, comportamento, imagem, escuta activa e empatia.

Palavras-chave: negociação, liderança, comunicação, liderança feliz.

JEL: I31 Bem-estar general, necessidades básicas, nível de vida, qualidade de vida, felicidade. 


\section{Introducción}

I liderazgo comunicacional y sus elementos constitutivos, la comunicación y el arte de la negociación, dan lugar a un novedoso concepto, el de liderazgo feliz.

Para llegar a este punto, antes tuve que hacer un breve recorrido por los principales anillos de la cadena que, finalmente, me llevaron a definir este concepto, con la esperanza de ayudar a muchos a balancear sus vidas e identificar la mágica receta que cada uno puede potencialmente desarrollar, con un extraordinario beneficio personal y profesional.

Todo ser humano tiene un factor innato y un set de elementos adquiribles, es decir, que pueden trabajarse a través de la práctica y de algunas herramientas que el presente estudio va a proponer. Estos elementos se resumen en los siguientes: concientización, comportamiento, imagen, escucha activa y empatía.

La concientización es un paso previo obligado no solo para activar los demás procesos -comportamiento, escucha activa, imagen y empatía-, sino para ejercer la función de lubricante entre ellos, permitiendo que interactúen de forma coherente y fluida.

Así, la concientización consiste en emprender un camino de autoanálisis e introspección para identificar nuestras fortalezas, debilidades, puntos de quiebre emocionales y potencialidades inexploradas.

Sin este paso, el ser humano sigue replicando patrones de conducta de forma rutinaria y repetitiva, no solo anulando ex ante toda posibilidad de cambio y reajustes, sino frustrando esta chispa creativa y rompedora que existe en cada persona, que permite salir de la zona de confort y explorar nuevos horizontes.

El comportamiento se refiere a la posibilidad que cada uno tiene de modificar algunos patrones de conducta en función de un objetivo prefijado: es 
decir, si yo vivo con una persona, tenderé a conseguir una mutua mejor calidad de vida que estar dispuesto a ceder en algunos aspectos de la convivencia: así, si ocurre que mi conviviente prefiere dormir con la ventana abierta, deberé ceder y acceder a ello, posiblemente a cambio de otro beneficio que la otra persona me otorgará, por ejemplo, cerrar el tubo de la pasta de dientes, cosa que antes esta persona no sentía la necesidad de hacer.

La escucha activa se refiere a la capacidad de saber escuchar de forma partícipe y genuina, con la idea de percibir toda la retroalimentación posible acerca de los principales intereses, preocupaciones y motivaciones de la contraparte. Este enfoque permitirá una serie de ventajas, desde la captación de valiosa información hasta la creación de un ambiente más amigable, en donde el otro, al sentirse escuchado, tendrá una mayor disposición a escucharnos a su vez. La empatía de fondo que surge es el tres d'union fundamental para cualquier proceso de comunicación. No es casualidad que la escucha activa representa la herramienta más estratégica del buen negociador (Stone, Patton y Heen 2000).

La imagen es el complemento natural de cualquier mensaje que quiera enviarse entre emisor y receptor: recubre, por ello, un papel especialmente significativo. Como se sabe, la comunicación es, por definición, un intercambio, un fluir de mensajes entre dos polos, emisor y receptor, pero ocurre que este proceso continuo es interrumpido por una infinidad de elementos distorsionantes e interferencias: distracciones, códigos errados, equivocada interpretación de una situación, entre otros.

Al darse estos escenarios, es inevitable que el mensaje que sale de una fuente sea alterado, confuso e incompleto, como mínimo, y allí es cuando el rol de la imagen se eleva a una función de complemento indispensable, por lo que estas fallas que caracterizan el proceso de comunicación se perfeccionan y definen.

La imagen completa el mensaje, el individuo mismo, podríamos decir, se transforma en mensaje; por ello, si utilizamos un determinado código de comunicación, este deberá resultar coherente con la imagen que estamos transmitiendo, que, a su vez, corresponde a cierta expectativa social; así, un médico deberá atender con un mandil blanco -lo que corresponde al imaginario colectivo con respecto a este rol- $\mathrm{y}$ no vestido de payaso o con una toga de juez. 
Finalmente, la empatía cierra el círculo de las herramientas que pueden aprenderse y consiste en la capacidad de conectar con el otro, de tal manera que nos ganamos al otro (Fisher, Kopelman y Kupfer Schneider 1996). Es la habilidad de saber captar, identificar y ajustarse a las preocupaciones, necesidades y motivaciones de la otra parte, por lo que vamos a transmitir solidaridad con su estado anímico y, a continuación, podremos desarrollar un clima propicio de diálogo y recíproca escucha activa (Fisher, Kopelman y Kupfer Schneider 1996).

La indispensabilidad de aprender a desarrollar destrezas empáticas es un reto que puede resultar bastante difícil para muchas personas, puesto que el ser humano es por definición egocéntrico y le cuesta salir de sí mismo para realmente ponerse "en el zapato del otro".

Sin embargo, es un esfuerzo absolutamente necesario, puesto que el proceso de toma de decisiones - muy a pesar de lo que muchos creen- pasa por las emociones, ya no por la razón.

Además, la empatía desencadena un proceso de progresiva mutua confianza y la confianza es el pivote alrededor del cual gira la totalidad de las relaciones humanas, desde los negocios hasta las relaciones de pareja.

Así, el liderazgo feliz podría representarse como una estrella de cinco puntas, que tiene dos brazos que interactúan, el comportamiento y la imagen, y dos patas sobre las que se sostienen, la escucha activa y la empatía. En la parte alta, se ubica el líquido transmisor, el lubricante que permite que todos estos componentes interactúen, la concientización: con este término, se quiere hacer referencia a la necesidad de asumir plena conciencia de todos los procesos que caracterizan la comunicación humana, desde el análisis introspectivo con el fin de identificar nuestros puntos de quiebre y nuestro emotional footprint, ${ }^{1}$ hasta las interacciones que realizamos en cualquier proceso negociador.

Cuando concientizamos, nos damos cuenta de las técnicas de negociación dura que la contraparte podría estar implementando; aplicamos la escucha activa captando información valiosa; detectamos amenazas, identificamos oportunidades; visualizamos tácticas, etcétera.

1. El emotional footprint describe básicamente la huella emocional, esto es, todas aquellas características y elementos de nuestras personalidades que determinan un set de elementos únicos en cada persona, haciéndola vulnerable en algunos contextos y fuerte en otros. Solo por medio de un proceso de concientización y autoanálisis del sujeto puede llegarse a identificar la huella emocional. 


\section{Tabla 1}

\section{Liderazgo feliz}

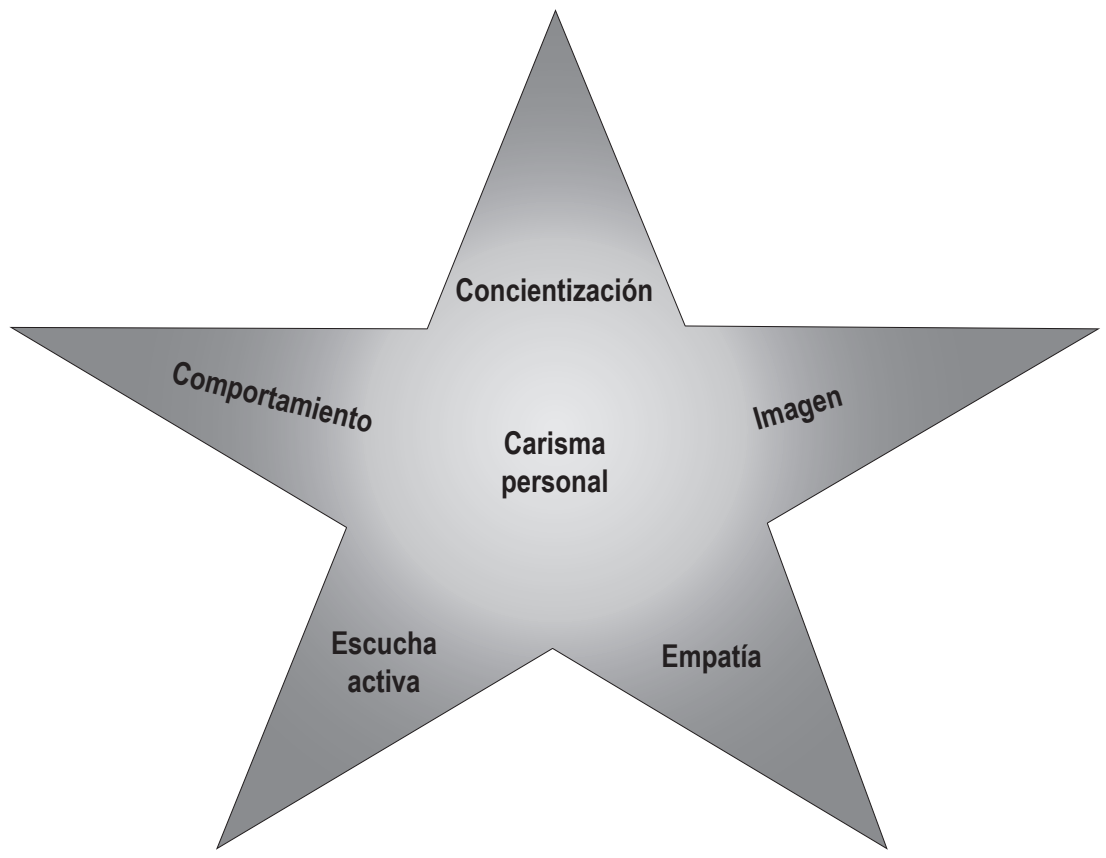

Fuente: el autor.

Elaboración propia.

Una vez definidos los cinco ejes de lo que puede aprenderse, es decir, de aquellas destrezas que si bien no estuvieran muy marcadas en nuestro código genético las podríamos desarrollar con relativo grado de satisfacción, pasamos a un elemento que, por otro lado, es innato: el carisma, es decir, aquella química mágica que poseen algunas personas para suscitar agrado y simpatía en el grupo, para motivar y generar entusiasmo acerca de algo o de alguien. Se trata de un don absolutamente único, tan excepcional como la genialidad de un pintor, o de un músico que toca el piano sin haber tomado jamás clases; es este elemento metafísico, por no caer en el terreno de las definiciones religiosas, que se halla misteriosamente en algunos seres humanos, un aliento sobrenatural que sopla en el interior de algunos 
privilegiados para que, a su vez, a través de sus dones, inspiren al resto, emocionando, motivando, guiando.

Finalmente, la buena noticia es que una comunicación exitosa puede resultar de los elementos que sí se aprenden -imagen, empatía, escucha activa, concientización-, más, eventualmente, ese elemento innato que es el carisma.

Este conjunto de ingredientes marca las pautas de un desarrollo personal exitoso y equilibrado, en donde el ser humano puede aspirar a un nuevo concepto de liderazgo feliz.

\section{El reto de la comunicación: los errores de comunicación más frecuentes y su impacto}

Todos comunicamos, en todo momento, como gesticulamos, como miramos, como actuamos, absolutamente todo lo que sale de nosotros comunica algo a alguien, proyecta una imagen determinada a nuestro entorno.

Así, al entrar en una habitación y al ver dos personas peleando y gritando, automáticamente, aun sin información acerca de la identidad de estas personas, acerca del conflicto y circunstancias existentes, nuestro cerebro recibirá un mensaje subliminal que hará procesar los hechos de alguna manera: a lo mejor, vamos a tener una mala impresión de estas personas, o el incidente producirá desconcierto, diversión u otros posibles escenarios perceptuales.

El hecho es que, independientemente de la voluntad, esta imagen producirá un conjunto de emociones que se traducirán en conclusiones y/o prejuicios (la persona A es quien está atacando la persona $\mathrm{B}$, o viceversa).

Dicho en otro modo, no solo comunicamos a través de códigos analógicos -las palabras que formulamos- sino a través de un complejo y articulado aparataje personal, desde nuestros gestos y posturas, hasta comportamientos y elementos de paralenguaje, como el tono de la voz, ritmo y acento, entre otros.

Estas consideraciones entrañan una consecuencia importante, no hay que centrarse únicamente en lo que vamos a decir, sino en cómo lo vamos a decir. Por ello, la imagen -física, corporal y sicológica- es fundamental y básica de la persona que está atrás de la formulación de una idea. Comunicar es la 
tarea más compleja del ser humano, puesto que justamente de esto depende la calidad de las relaciones humanas, desde los ámbitos personales hasta los profesionales.

El lado bueno es que, con un previo proceso de concientización y el planteamiento de una oportuna estrategia de reset emocional, pueden desarrollarse destrezas comunicacionales que sin lugar a dudas ayudarán a mejorar nuestro potencial como comunicadores, lo que interesa sumamente, en la medida en que un buen comunicador es un buen negociador, y un buen negociador acaba identificándose con un buen líder.

Por otro lado, a pesar de su importancia fundamental, se trata de un terreno insidioso, poco explorado en muchas áreas de conocimiento -solo pensemos en qué mal estructurada y poco homogénea está la comunicación global de temas trascendentes como el cambio climático-y sujeto a una multitud de peligros; veamos algunos de ellos a la luz de los axiomas de Watzlawick.

Toda comunicación tiene un nivel de contenido y uno de relación, por lo que, más allá de las palabras que utilicemos en un discurso, existe un significado más profundo, que es el que nosotros damos a estas palabras y oraciones y que no necesariamente será interpretado del modo que queremos por el receptor del mensaje. Dicho de otra forma, hay que adaptar los diferentes códigos a la persona, el código del mensaje es correcto si toma en cuenta la situación del receptor puesto que hay códigos culturales compartidos y no compartidos, además de una infinidad de diferencias asociadas a edad, género, nivel socioeducativo, entre otras.

Así, una mala interpretación de la situación -debido a la utilización de códigos distintos-define un error de comunicación muy frecuente; este sería, por ejemplo, el caso de un conferenciante quien, invitado a dirigirse a un público de niños de secundaria de un colegio, no reajuste su discurso "técnico" a las características de madurez de su público, lo que daría como resultado una total desconexión entre fuente (el mismo) y receptores (los estudiantes).

Finalmente, otro tema muy recurrente se presenta cuando la comunicación digital (lo que decimos) no concuerda con la comunicación analógica (el cómo decimos), por lo que el receptor recibe un mensaje confuso o lo malinterpreta.

Algo parecido ocurre cuando se confunde contenido (palabras) y relación (significado), esto es, debido a que el uso que le damos a las palabras 
no coincide a menudo con el significado percibido por la contraparte, lo que a su vez es imputable a que cada uno de nosotros resulta ser el complejo resultado de procesos de socialización primaria y secundaria muy diferentes, lo que hace que nuestra forma de dar significado a las cosas sea igualmente muy diferente.

Un último gran desafío de la comunicación -no de casualidad muy considerado en el proceso de preparación de un buen negociador- es el de la escucha activa, puesto que el business as usual de nuestra interacción con el entorno no contempla mucho esta importantísima herramienta.

Esto ocurre por una serie de obstáculos, estamos llenos de pensamientos tóxicos, sentimientos, prejuicios y no sentimos que hay espacio para lo que los otros puedan decir; nos percibimos como un producto acabado y, por último, a menudo consideramos que escuchar es una pérdida de tiempo.

Contrariamente a lo que se debería hacer, el ser humano tiende a juzgar, por lo que asumimos que los pensamientos de otros son equivocados; pre-

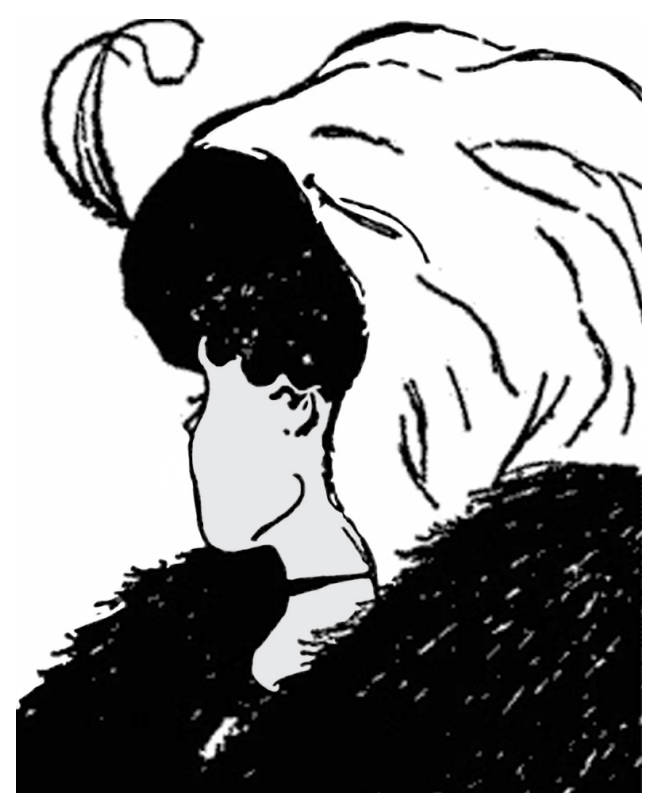

¿Qué ven aquí, una mujer joven o una anciana? 
paramos nuestra respuesta porque estamos a la defensiva, porque sentimos tener que dar consejos, o, sencillamente, nuestra mente se distrae y acabamos pensando "si hay suficiente comida para la cena con los parientes".

Es evidente que el mundo de la comunicación sea profundamente complejo, como resultado de la complejidad de las relaciones humanas y del hecho que nos movemos en un terreno más emocional que racional, lo que impone detectar y no subestimar el rol de los sentimientos, ajenos y nuestros (Fisher, Ury y Patton 2001).

De igual modo, cada ser humano tiene su propia percepción frente a cualquier estímulo externo, lo que no necesariamente coincide con la realidad de las cosas.

Estamos en el mundo del más total relativismo, donde no solo se enfrentan todas estas interferencias, sino que influye todo ese enredo de factores endógenos y exógenos que definen de modo único a cada persona (Fisher, Ury y Patton 2001).

\section{Los ingredientes de una buena estrategia de comunicación: enfoque analítico, información y preparación}

Los pasos para una buena estrategia de comunicación y de negociación pasan por decidir qué decir y cómo decirlo, según las más elementales instrucciones estratégicas de Joseph Napolitano.

Esos pasos incluyen a quién voy a dirigirme, midiendo cómo enunciar un mensaje en consideración de una serie de factores, contemplados dentro del marco del Paradigma de Laswell.

Según este, lo importante es el mensaje, que tiene que llegar del modo deseado, puesto que el emisor codifica el mensaje, pero el receptor, por su lado, lo decodifica. A esto se añade que la comunicación es segmentada, por lo que nuestra forma de comunicarnos, y los medios que para estos efectos escogeremos, dependerá del público objetivo al que nos dirigimos.

Como consecuencia, la elaboración de una buena estrategia pasara por una serie de fases: análisis de emisores, análisis del mensaje, análisis de medios, análisis de audiencia y de efectos. El establecimiento de la secuencia de 
"quién dice qué, a través de qué medios, dirigidos a qué público y con cuáles efectos" es de fundamental importancia.

Tabla 1

\section{Paradigma de Laswell}

\begin{tabular}{|l|l|}
\hline Quién dice & Análisis de emisores \\
\hline Qué & Análisis de mensaje \\
\hline A través de qué medio & Análisis de medios \\
\hline A quién & Análisis de audiencia \\
\hline Con qué efecto & Análisis de efectos \\
\hline
\end{tabular}

Fuente: Paradigma de Laswell.

Elaboración propia.

Finalmente, deberá tenerse cuidado con todo tipo de distracciones, ya que, así sean provocadas para sabotear la comunicación o sean casuales, el resultado es el mismo: desenfocan el mensaje y generan ruido.

Dentro de este marco estratégico debe considerarse otro elemento básico: la importancia-sobre todo a la hora de entablar procesos de negociación- de estar informados, preparados; cuanto más se sepa de lo que se va a negociar (deal terms) y de la contraparte (hábitos, cultura, nivel socioeconómico, debilidades y fortalezas), tanto más sólida y blindada será nuestra posición.

El estar informados implica no solo el convencional proceso de recolección de información útil y pertinente, sino también un proceso de escucha activa, que pase por negociar con nuestra voz interior obligándonos a ser genuinamente curiosos, a resistir a la tentación de juzgar, estar a la defensiva y dar consejos. Al contrario, la idea es librarnos de prejuicios y ser auténticos, puesto que un común desacierto, a la hora de comunicar, pasa por subestimar nuestra audiencia y asumir que su nivel de educación y/o inteligencia no les permite entendernos.

Por otro lado, cabe destacar la importancia de cuidarse de situaciones de infracarga, al igual que de situaciones de sobrecarga. La primera se da cuando se decide sin la información correcta, adecuada y confiable, lo que lleva a una equivocación casi segura. 
Al revés, las situaciones de sobrecarga son aquellas en donde hay demasiada información, lo que, por otro lado, bloquea dramáticamente nuestra capacidad de decisión, tanto que, entre las dos, es en todo caso preferible la primera.

Concluyendo, cuando se plantea una estrategia de comunicación no debe actuarse nunca "con intuición", sino con preparación, y una que sea meticulosa y detallada. Si se sabe gestionar la información, es posible que pueda inclusive desactivarse una crisis antes que se genere, lo que añade un extraordinario potencial a su adecuado y tempestivo manejo.

\section{El poder de la comunicación en el arte de la negociación}

Según Manuel Castells, comunicar es compartir significados mediante el intercambio de información. En esta definición el proceso de la comunicación queda definido por la tecnología de la comunicación, las características de los emisores y receptores de la información, así como por sus códigos culturales, protocolos de comunicación y alcance del proceso.

Es justamente en este punto donde comunicar y negociar encuentran su punto de comunión, debido a que la negociación no es otra cosa sino el arte de la comunicación en su máxima expresión, un ámbito en el que se pretende conjugar las necesidades de las personas para alcanzar mutuos beneficios (Castells 2010).

Sobre este trasfondo, la comunicación es un proceso que permite a la información pasar de una entidad emisora a una receptora, una interacción centrada en un repertorio de signos y reglas semióticas comunes entre partes.

Con el fin de que realmente esta interacción sea exitosa deberá actuar el liderazgo personal y potencial negociador de toda persona, puesto que -como se ha destacado en varias ocasiones- la comunicación representa el eje más problemático de las relaciones humanas; si esta se traba, es interrumpida o se asienta sobre premisas equivocadas, todo proceso negociador será mal direccionado y no se darán los resultados deseados, sin mencionar el caso de contextos sicológicos y barreras culturales distintas, lo que complica sobremanera el cuadro (Mnookin, Peppet y Tulumello 2000). 
Sobre este trasfondo, el arte de la negociación representa una estrategia fundamental en la toma de decisiones, un proceso mediante el cual las partes, en cualquier ámbito, disciplina y profesión, resuelven conflictos y llegan a acuerdos con beneficios y ventajas para todos los involucrados considerando necesidades e intereses particulares.

Tanto los altos líderes, como personas a todo nivel y de todo colectivo, entienden la importancia de desarrollar destrezas y competencias que fortalezcan sus capacidades negociadoras y estas, a su vez, serán el reflejo de su capacidad de comunicarse.

Confluyendo con las tendencias actuales de analizar y entender el mundo, la negociación es un eje transversal de estudio que atraviesa todas las esferas de la vida, desde el ámbito más íntimo y familiar hasta los circuitos más excluyentes de las reuniones multilaterales y globales.

En cuanto a las maneras de negociar, existen diferentes tipologías negociadoras como son: ganar-perder (método adversario); perder-perder (método competitivo); y ganar-perder. El método de Harvard - que a fecha de hoy representa la escuela más prestigiosa en cuanto a negociación y liderazgo a nivel mundial- se diferencia en la medida en que busca llegar a acuerdos de una forma cooperativa, de manera que las partes lleguen a una situación de ganar-ganar.

Por otro lado, la negociación, tal y como acostumbramos a utilizarla según el business-as-usual de nuestra cultura adversaria y competitiva, se reduce a un regateo que tiene por objeto lo que se esté transando; sin embargo, el método de Harvard señala que no solamente se debe negociar lo que está "sobre la mesa", sino que se debe llevar la negociación a un punto en donde se puedan generar beneficios adicionales, lo que eleva esta poderosa herramienta mucho más allá que un mero papel distributivo; generar un valor agregado con visión de futuro, asegurar nuestro acuerdo en el largo plazo y cuidar el aspecto relacional con la contraparte pasan entonces a ser los nuevos ejes de la metodología, evidenciando una nueva concepción de fondo.

Finalmente, el cuidado por el aspecto relacional presente y futuro demuestra como la negociación se plantee como una herramienta de comunicación, antes que un medio para conseguir un resultado inmediato.

Tanto la comunicación como el arte negociador se caracterizan por una dualidad de fondo: siempre implican una contraparte, ya sea un individuo o 
un colectivo más o menos numeroso y siempre representan una doble vía de conversación. Finalmente, una vez que -con la práctica y el debido respaldo teórico- podamos manejarnos en el océano insidioso de las tácticas de negociación dura (hard bargaining), nos daremos cuenta del enorme potencial que tenemos en todas las esferas de nuestra vida; aprenderemos a conocernos a nosotros mismos, dentro de un enfoque crítico que perfeccionará nuestras habilidades comunicacionales y que, finalmente, nos ayudará a ser líderes creativos y agentes de cambio.

\section{El liderazgo y el arte de la negociación: dos caras de la misma moneda}

Una buena comunicación implica saber escuchar al otro. Si entiendes sus necesidades, entenderás sus intereses y podrás negociar cualquier cosa y, finalmente, si eres un buen negociador, también serás un gran líder.

Por su lado, el liderazgo es la capacidad de comunicarse con un grupo de personas, influir en sus emociones para que se dejen guiar y dirigir hacia el cumplimiento de un objetivo.

De igual modo, el liderazgo implica la capacidad de influir para que el grupo ejecute las acciones necesarias en cumplimiento de este objetivo.

Así, el líder es un inspirador, que fija el rumbo hacía un futuro, motiva la dedicación individual, suscita compromisos en los seguidores y tiene capacidad organizacional.

Sobre este trasfondo, es evidente que el líder es un comunicador, que sabrá escuchar para aprender del otro y sintonizarse sobre sus necesidades y prioridades, lo que le permitirá tomar decisiones acertadas: el líder practica la escucha activa, porque esta poderosa herramienta es justamente la puerta que permite el acceso al otro, a su mundo e intereses. Aparte, sabe que escuchar a veces -como cuando desconocemos información- es mucho más útil que hablar, en la medida en que el feedback generado desencadenará automáticamente otros procesos fructíferos de comunicación y atención recíproca, lo que finalmente generarán un clima de confianza que asentará las bases de relaciones y acuerdos más duraderos en el largo plazo. 
Conforme integramos nuevos comportamientos, experimentaremos algunos elementos que podrían desestabilizarnos, como la resistencia, es decir, una natural tendencia a apegarnos a los que nos resulta familiar, y la incertidumbre, puesto que cuando empezamos a aplicar nuevas destrezas nos podemos sentir hipócritas.

Por otro lado, con la práctica nos sentiremos progresivamente menos falsos y más cómodos con el nuevo comportamiento, por lo que entraremos en la fase de asimilación.

A la larga, en la medida en que comenzaremos a aplicar estos comportamientos en otras situaciones, dando lugar a conductas de transferencia y réplica, de forma inconsciente y automática comenzaremos a insertar nuevos patrones en nuestro repertorio, promoviendo así el fenómeno de la integración. En otras palabras, el líder no se siente un producto acabado: al contrario, sabe que no sabe -famosa expresión del filósofo griego Sócrates (siglo V $\mathrm{aC})-\mathrm{y}$ aprende a mirar atrás para poder mirar adelante.

\section{Conclusiones: \\ el liderazgo feliz como natural combinación de herramientas del liderazgo comunicacional}

La persona que aprende a comunicar -estructurando las herramientas que se han descrito en este breve trabajo- sabrá emprender procesos de interacción acertados en su entorno y quienes adquieren conciencia de saber gestionar estas habilidades acaban siendo líderes, heredando al mismo tiempo la responsabilidad de guiar a otros en este proceso de aprendizaje sutil y profundo.

De igual modo, la escalada de conflictos que a menudo se genera por no saber gestionar nuestros puntos de quiebre emocionales, nuestro temperamento, será mucho más controlada $\mathrm{y}$, al contrario, muchas situaciones problemáticas podrán ser desactivadas antes de presentarse.

El líder feliz es aquella persona que aprende a balancearla escucha activa con el comportamiento, la imagen y la empatía, balanceo que le llevará a un equilibrio entre sí mismo y el entorno; como consecuencia, sus com- 
portamientos e imagen serán alineados y coherentes, mientras que un constante proceso de concientización garantizará la debida retroalimentación y los eventuales ajustes necesarios, puesto que permitirá enfocar siempre en dónde estamos.

Asimismo, el líder feliz sabrá negociar oportunamente diferentes agendas, ponderando entre sus necesidades y una razonable satisfacción de las necesidades ajenas, privilegiando el eje relacional porque sabe que lo que un acuerdo que no concreta hoy con una determinada contraparte, podría aparecer de nuevo en un momento futuro, y podrá materializarse solo si se cuidó una buena relación.

El líder feliz es una persona que sabe guiar al grupo, consciente de su rol favorecido en cuanto a saber manejar y gestionar los conflictos existentes, evitando que estos escalen y anticipando aquellos latentes; es consciente de que nos desenvolvemos en un mundo de recursos escasos y que -aparte los materiales-, existen factores intangibles como el tiempo y el desgaste emocional, que son hasta más valiosos y que requieren de decisiones acertadas y bien enfocadas antes de emprender cualquier interacción humana.

En resumen, se trata de un agente de cambio consciente, que lidia serenamente con sus limitaciones humanas, pero que, a diferencia del resto, sabe gestionarlas con sabiduría y mente fría, enfocándose en sus fortalezas y balanceándolas con las debilidades, por lo que cuando viene atacado por factores exógenos sabe balancearse rápidamente y no pierde el control de una discusión o de una negociación.

Como puede apreciarse, se han analizado brevemente una serie de herramientas aparentemente básicas, parte de un manual de instrucciones que parece haber estado siempre presente encima de nuestro escritorio, pero que por alguna razón nunca se le prestó la debida atención o no se lo articuló en un único círculo virtuoso.

Si estaremos dispuestos a realizar un reajuste interior a la luz de estos hallazgos, mejoraremos notablemente nuestra calidad de vida ya que nuestro potencial de comunicación -y por ende de negociación- se verá exponencialmente incrementado y los conflictos se podrán manejar al menor costo posible.

En conclusión, no podremos evitar que la comunicación falle y que haya un inevitable desperdicio de tiempo, energía, o un desgaste de las relaciones, 
ya que la misma complejidad de las relaciones humanas conllevará siempre situaciones de falla en la mutua identificación de intereses, percepciones, códigos comunicacionales... pero, sin lugar a dudas, recurrir a las armas que la metodología negociadora pone al alcance será de gran ayuda para un verdadero liderazgo feliz.

\section{Referencias}

Castells, Manuel. 2010. Comunicación y poder. Madrid: Alianza.

Club Planeta. s. f. Características de un líder. Consulta: marzo de 2014. «http://www.trabajo. com.mx/caracteristi cas_de_un_lider.htm>.

Fisher, Roger, Elizabeth Kopelman y Andrea Kupfer Schneider. 1996. Beyond Machiavelli: Tools for Coping With Conflict. Nueva York: Penguin Group.

Fisher, Roger, William Ury y Bruce Patton. 2001. Getting to Yes: Negotiating Agreement Without Giving in. Nueva York: Penguin Group.

Linda Cristina [?]. 2012. Modelos clásicos de comunicación. Consulta: abril de 2014. «http:// lindacristina16.blogspot.com/2012/02/formula-de-laswell-o-paradigma-de.html .

Mnookin, Robert, Scott Peppet y Andrew Tulumello. 2000. Beyond Winning. Negotiating to Create Value in Deals and Disputes. Cambridge: Harvard University Press.

Napolitano, Joseph. 2010. 15 recomendaciones de Joseph Napolitano. Video. 7'15". Consulta: enero de 2014. 〈https://www.youtube.com/watch?v=6xHjfjFboYw\&noredirect=1〉.

Stone, Douglas, Bruce Patton y Sheila Heen. 2000. Difficult Conversations: How to Discuss what Matters the Most. Nueva York: Penguin Group. 